\title{
MENGUKUR KINERJA DISTRIBUSI BATU-BARA OLEH UKM DARI TAMBANG HINGGA PELABUHAN
}

\author{
Hendy Tannady ${ }^{1}$, Dino Caesaron ${ }^{2)}$ \\ ${ }^{1}$ Fakultas Teknologi dan Disain, Universitas Bunda Mulia \\ email: hendytannady@bundamulia.ac.id \\ ${ }^{2}$ Fakultas Teknologi dan Disain, Universitas Bunda Mulia \\ email: dcaesaron@bundamulia.ac.id
}

\begin{abstract}
At present, a logistic services for coal manufacturer company is very important. However, often happen that production process goes faster than logistic services in delivery mining product from the mining area to the port. DEA (Data Envelopment Analysis) is expected will produce a parameter that can use to justified whether the perfomance of the job effective and efficient. This research will focus on evaluating the performance of four Small Medium Enterprise which operate their business in delivering the coal mining, from the mining area to the harbour. Element of the input is the number of the truck, loading and unloading manpower, and the number of truck which is return in one hour. Element of the output is the number of coal mining at the port. After data is analyzed by WinQSB, the conclusion is obtained that SME C and D operate better In terms of efficiency and optimization of than SME A and B.
\end{abstract}

Keywords: Logistic, Coal, Data Envelopment Analysis

\begin{abstract}
Abtract
Distribusi menjadi bagian penting dalam proses penyampaian produk dari produsen ke konsumen akhir. Penelitian ini akan mengukur efisiensi empat Usaha Kecil Menengah yang melayani jasa logistik pada perusahaan tambang yang berbeda di Kalimantan Tengah dengan analisis DEA. diketahui bahwa tidak semua usaha logistik tersebut telah berfungsi secara maksimal. Metode DEA digunakan dengan syarat harus adanya perbandingan unit terhadap subyek yang hendak diteliti, pada kasus perbekalan batubara ini, Semoga temuan yang terjadi dapat menjadi masukan yang berarti buat perusahaan dan menjadi bahan pembelajaran bagi pembaca untuk dapat memahami metode DEA.
\end{abstract}

Kata Kunci: Logistik, Batu bara, DEA (Data Envelopment Analysis)

\section{PENDAHULUAN}

Distribusi menjadi bagian penting dalam proses penyampaian produk dari produsen ke konsumen akhir. Pendistribusian yang tepat dan kuat akan menghantarkan suatu perusahaan atau organisasi pada

kesuksesan bisnis. Sebaliknya, pendistribusian yang lemah akan menghantarkan perusahaan pada kebangkrutan atau sekedar bertahan 
di tengah persaingan pasar (Grunt, 2009).

Permasalahan

pendistribusian sangat erat hubungannya dengan efisiensi biaya transportasi. Masalah yang umum berkaitan dengan pendistribusian suatu komoditi dari sembarang kelompok pusat pemasok yang disebut sumber, ke sembarang pusat penerima yang disebut tujuan, yaitu efisiensi atau meminimumkan biaya distribusi total (Ismaniah, 2009). Efisiensi dapat didefinisikan sebagai perbandingan antara keluaran (output) dengan masukan (input), atau jumlah keluaran yang dihasilkan dari satu input yang digunakan. Menurut Permono (2000), suatu perusahaan dikatakan efisien apabila: (1) mempergunakan jumlah unit input yang lebih sedikit dibandingkan jumlah input yang digunakan oleh perusahaan lain dengan menghasilkan jumlah output yang sama, (2) menggunakan jumlah unit input yang sama, tetapi dapat menghasilkan jumlah output yang lebih besar. Penelitian ini bertujuan untuk mengukur tingkat efisiensi Usaha Kecil Menengah (UKM) pada suatu daerah di Kalimantan Tengah yang menjadi andalan para pengusaha komoditi batu bara dalam pendistribusian atau logistik komoditi mereka. Sebagai dasar pengukuran efisiensi masing-masing UKM yang terlibat, digunakan analisis DEA (Data Envelopment Analysis), yaitu alat analisis yang didasari teknik programa linear untuk mengukur efisiensi relatif dari sekumpulan unit yang dapat diperbandingkan (Nugroho, 1995). Pengukuran efisiensi melibatkan empat UKM yang melayani jasa logistik pada perusahaan tambang yang berbeda di Kalimantan Tengah. Penjelasan pengukuran efisiensi oleh analisis DEA akan dijabarkan pada bab berikutnya.

\section{TINJAUAN KEPUSTAKAAN}

\section{Efisiensi}

Menurut Mumu D Huri \& Indah Susilowati (2004), efisiensi adalah perbandingan antara masukan (input) dan keluaran (output). Efisiensi telah dibahas oleh banyak peneliti pada beberapa 
kajian bidang keilmuan, seperti efisiensi waktu produksi yang dikaitkan dengan implementasi dari prinsip kerja 5S (Gunawarman \& Fanni, 2008), pengaruh merger dan akuisisi terhadap efisiensi Perbankan di Indonesia (Ruddy, 2010) dan efisiensi belajar mengajar dengan model e-learning (Inayatulloh, 2013).

\section{Data Envelopment Analysis (DEA)}

Menurut Soteriou \&
Stavrinides (2000) yang juga
mengutip dari Charnes dkk (1978)
Data Envelopment Analysis (DEA)

merupakan teknik pemrograman matematika yang pertama kali dikembangkan oleh Charnes dkk pada tahun 1978, sedangkan menurut Talluri (2000) Data Envelopment Analysis (DEA) adalah suatu alat untuk melakukan evaluasi juga meningkatkan kinerja dari operasi manufaktur dan jasa. Data Envelopment Analysis juga merupakan metode non parametrik untuk mengevaluasi efisiensi relatif dari unit pengambil keputusan pada basis yang melibatkan banyak masukan (input) dan keluaran (output) (Despotis \& Smirlis, 2001). Gonzales (2007) juga mengutarakan hal yang hampir serupa dengan Despotis \& Smirlis, yakni DEA merupakan metode penilaian untuk mengukur efisiensi dari suatu yang diamati dengan menggunakan banyak masukan dan keluaran. DEA dapat digunakan untuk mengukur efisiensi dan memiliki karakter berbeda dengan konsep pengukuran tingkat efisiensi pada umumnya, efisiensi yang diukur oleh DEA adalah yang bersifat teknis, analisis DEA hanya memperhitungkan nilai absolut dari suatu variabel (Mumu D Huri \& Indah Susilowati, 2004), kemudian nilai efisiensi yang dihasilkan bersifat relatif, yang artinya hanya dapat dibandingkan dengan sekumpulan unit dalam ruang lingkup komparasi DEA (Nugroho, 1995).

\section{Pengumpulan Data Primer}

Menurut Sugiyono (2009) pengumpulan data primer adalah pengumpulan data dimana peneliti atau pihak yang berkepentingan atas data, langsung terjun ke lapangan 
atau tempat obyek permasalahan untuk melakukan pencarian dan pengumpulan data. Data diperoleh oleh peneliti langsung dari sumber pertama. Data yang dikumpulkan digunakan untuk menyelesaikan permasalahan yang dimiliki peneliti.

\section{Pengukuran Tingkat Efisiensi}

Cara pengukuran yang dilakukan dalam Data Envelopment Analysis adalah dengan membandingkan antara output dan input yang ada (Ramanathan, 2000). Efisiensi = Output $:$ Input. Nilai Efisiensi suatu unit berkisar antara 0 sampai dengan 1. Decision Making Units (DMU) dikatakan efisien apabila:

1. Dari segi orientasi Output.

- Efisiensi naik, apabila Output naik saat Input tetap

- Efisiensi naik, apabila Output tetap saat Input turun

2. Dari segi orientasi Input.

- Efisiensi naik, apabila Input tetap saat Output naik

- Efisiensi naik, apabila Input turun saat Output tetap

Banyak sekali badan usaha yang memiliki sistem terintegrasi di bumi ini. Kualitas dari produktivitas dan efisiensi adalah beberapa diantara sekian banyak besaran yang diterima orang untuk dapat menggambarkan ukuran kinerja dari suatu sistem. Diharapkan metode Data Envelopment Analysis dapat menjawab dua pertanyaan yang sering kali muncul, yaitu: 1) Apakah suatu unit dalam suatu sistem usaha sudah beroperasi secara efisien? dan 2) Apabila belum, dalam hal apakah unit usaha itu belum beroperasi secara efisien? Analisis untuk menjawab kedua pertanyaan itu adalah Data Envelopment Analysis, diperkenalkan oleh J. Callen pada tahun 1991. Untuk menjawab pertanyaan No. 1, yaitu apakah suatu unit dalam suatu sistem usaha sudah beroperasi secara efisien? Mekanisme analisis dalam DEA terdiri atas 5 langkah. Lima langkah tersebut adalah sebagai berikut:

1. Memilih sistem yang Decision Making Unit (DMU)-nya akan dikaji efisiensinya (catatan: selanjutnya DMU akan disingkat menjadi "unit". 
2. Mendefinisikan besaran input yang tersedia untuk, dan besaran output yang dihasilkan oleh setiap unit yang akan dikaji efisiensinya.

3. Mendefinisikan variabelvariabel yang menggambarkan nilai dari satu satuan input serta satu satuan output.

4. Mendefinisikan variabel yang menggambarkan efisiensi dari setiap unit.

5. Merumuskan model matematis untuk setiap unit (meliputi perumusan fungsi tujuan dan kendalanya).

\section{Dalam merumuskan model}

matematis ini pada Langkah-5 digunakan 4 (empat) pendekatan sebagai berikut:

1. Untuk menyederhanakan perhitungan, lakukan scaling (penskalaan) terhadap nilai total input unit I dengan menyamakannya dengan nilai 1 (satu).
2. Terhadap efisiensi dari unit ke-I diusahakan untuk memaksimumkannya.

3. Tak ada unit yang efisiensinya lebih dari $100 \%$.

4. Setiap nilai output $\mathrm{t}_{\mathrm{r}}$ maupun nilai input $w_{s}$ haruslah bernilai positif (+).

\section{HASIL DAN PEMBAHASAN}

Pada pembahasan studi kasus yang digunakan adalah mengukur efektivitas dan efisiensi dari jasa logistik UKM. Dengan mempertimbangkan sumber daya yang dimiliki oleh UKM tersebut baik itu sumber daya transportasi maupun manusia, dapat kita analisa apakah hasil yang dihasilkan oleh setiap UKM tersebut sudah wajar dan efektif atau masih belum dianggap optimal.

Berikut adalah data dalam bentuk tabel jumlah input dan output: 
Tabel 1. Data Input dan Output dari 4 UKM yang Melayani Jasa Pengangkutan Batubara Input Output

UKM

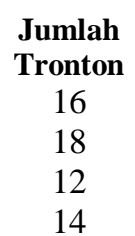

Jumlah Tenaga
Loading
15
13
11
16

Jumlah Tronton yang
kembali dalam 1 jam
0.6
0.8
0.7
0.4

Jumlah Batubara di

Pelabuhan (Ton)/hari 550

620

580

570

Langkah yang harus dilakukan adalah mendefinisikan variabel yang menggambarkan efisiensi dari setiap unit. Efisiensi dari UKM ini adalah sebagai berikut:

$\frac{\text { nilai total dari output unit ke } i}{\text { nilai total dari input unit ke } i}$

Dari Tabel 1, efisiensi keempat unit adalah sebagai berikut:

Efisiensi UKM A =

$$
\frac{550 t 1}{16 w 1+15 w 2+0,6 w 3}
$$

Efisiensi UKM B =

$$
\frac{620 t 1}{18 w 1+13 w 2+0,8 w 3}
$$

Efisiensi UKM C = $580 t 1$

$$
\overline{12 w 1+11 w 2+0,7 w 3}
$$

Efisiensi UKM D =

$570 t 1$

$$
\overline{14 w 1+16 w 2+0,4 w 3}
$$

Kendala Penskalaan:

- UKM A: $16 w_{1}+15 w_{2}+0.6 w_{3}=1$

- UKM B: $18 w_{1}+13 w_{2}+0.8 w_{3}$ $=1$

- UKM C: $12 w_{1}+11 w_{2}+0.7 w_{3}=1$

UKM D: $14 w_{1}+16 w_{2}+0.4 w_{3}=1$

\section{Kendala Efisiensi:}

- UKM A: $-550 t_{1}+16 w_{1}+15 w_{2}+$ $0.6 w_{3} \geq 0$

- UKM B: $-620 t_{1}+18 w_{1}+13 w_{2}+$ $0.8 w_{3} \geq 0$

- UKM C: $-580 t_{1}+12 w_{1}+11 w_{2}+$ $0.7 w_{3} \geq 0$

- UKM D: $-570 t_{1}+14 w_{1}+16 w_{2}+$ $0.4 w_{3} \geq 0$

\section{Nilai Max Z:}

- UKM A: $\max \mathrm{z}=-550 t_{1}$

- UKM B: $\max \mathrm{z}=-620 t_{1}$

- UKM C: $\max \mathrm{z}=-580 t_{1}$

- UKM D: $\max \mathrm{z}=-570 t_{1}$

Dengan membuat model matematis berbentuk programa linear, berikut persamaan linear yang dapat digunakan untuk mengkaji efisiensi masing-masing UKM. Persamaan Linear berikut 
adalah pemrograman linear dari

UKM A, B, C, dan D:

\section{Pemrograman Linear UKM A}

Fungsi Tujuan: $\max z=550 t_{1}$

Kendala:

$$
\begin{aligned}
& -550 t_{1}+16 w_{1}+15 w_{2}+0.6 w_{3} \geq 0 \\
& -620 t_{1}+18 w_{1}+13 w_{2}+0.8 w_{3} \geq 0 \\
& -580 t_{1}+12 w_{1}+11 w_{2}+0.7 w_{3} \geq 0 \\
& -570 t_{1}+14 w_{1}+16 w_{2}+0.4 w_{3} \geq 0 \\
& 16 w_{1}+15 w_{2}+0.6 w_{3}=1 \\
& t_{1}, w_{1}, w_{2}, w_{3}>0.001
\end{aligned}
$$

\section{Pemrograman Linear UKM B}

Fungsi Tujuan: $\max z=620 t_{1}$

Kendala:

$$
\begin{aligned}
& -550 t_{1}+16 w_{1}+15 w_{2}+0.6 w_{3} \geq 0 \\
& -620 t_{1}+18 w_{1}+13 w_{2}+0.8 w_{3} \geq 0 \\
& -580 t_{1}+12 w_{1}+11 w_{2}+0.7 w_{3} \geq 0 \\
& -570 t_{1}+14 w_{1}+16 w_{2}+0.4 w_{3} \geq 0 \\
& 18 w_{1}+13 w_{2}+0.8 w_{3}=1 \\
& t_{1}, w_{1}, w_{2}, w_{3}>0.001
\end{aligned}
$$

\section{Pemrograman Linear UKM C}

Fungsi Tujuan: $\max z=580 t_{1}$

Kendala:

$$
\begin{aligned}
& -550 t_{1}+16 w_{1}+15 w_{2}+0.6 w_{3} \geq 0 \\
& -620 t_{1}+18 w_{1}+13 w_{2}+0.8 w_{3} \geq 0 \\
& -580 t_{1}+12 w_{1}+11 w_{2}+0.7 w_{3} \geq 0 \\
& -570 t_{1}+14 w_{1}+16 w_{2}+0.4 w_{3} \geq 0 \\
& 12 w_{1}+11 w_{2}+0.7 w_{3}=1 \\
& t_{1}, w_{1}, w_{2}, w_{3}>0.001
\end{aligned}
$$

\section{Pemrograman Linear UKM D}

Fungsi Tujuan: $\max \mathrm{z}=570 t_{1}$

Kendala:

$$
\begin{aligned}
& -550 t_{1}+16 w_{1}+15 w_{2}+0.6 w_{3} \geq 0 \\
& -620 t_{1}+18 w_{1}+13 w_{2}+0.8 w_{3} \geq 0 \\
& -580 t_{1}+12 w_{1}+11 w_{2}+0.7 w_{3} \geq 0 \\
& -570 t_{1}+14 w_{1}+16 w_{2}+0.4 w_{3} \geq 0 \\
& 14 w_{1}+16 w_{2}+0.4 w_{3}=1 \\
& t_{1}, w_{1}, w_{2}, w_{3}>0.001
\end{aligned}
$$

$$
\text { Setelah melakukan }
$$

perhitungan secara menyeluruh terhadap kemampuan variabel dalam mempengaruhi nilai z, UKM tersebut dianggap sudah beroperasi secara efektif dan efisien apabila nilai z adalah 1. Setelah melakukan perhitungan diketahui bahwa hasil akhir untuk nilai z pada UKM A dan UKM B adalah dibawah satu (<1). Sehingga dapat dikatakan bahwa kinerja yang telah dilakukan oleh kedua UKM tersebut belum cukup efisien antara hasil yang diperoleh (output) dengan sumber daya (input) yang dimiliki. Sehingga agar dapat dikatakan maksimal dan efisien, kedua UKM tersebut harus meningkatkan output yang dalam penelitian ini output yang dimaksudkan adalah jumlah 
batubara yang berhasil di turunkan di pelabuhan dalam 1 hari kerja. Dengan adanya temuan bahwa UKM A dan B belum berfungsi secara maksimal dibandingkan dengan UKM C dan D, maka sebaiknya melakukan benchmarking terhadap dua UKM yang telah beroperasi secara optimal tersebut.

\section{PENUTUP}

Sebuah sistem distribusi atau logistik yang mumpuni akan sangat membantu dalam proses rantai pasok di antara produsen dan konsumen, setelah melakukan pengumpulan data terhadap empat usaha logistik yang mengangkut batubara di daerah Kalimantan Tengah, akhirnya diketahui bahwa tidak semua usaha logistik tersebut telah berfungsi secara maksimal. Dalam hal ini metode DEA digunakan dengan syarat harus adanya perbandingan unit terhadap subyek yang hendak diteliti, pada kasus perbekalan batubara ini, penelitian membandingkan empat usaha logistik yang melayani empat perusahaan tambang batubara. Semoga temuan yang terjadi dapat menjadi masukan yang berarti buat perusahaan dan menjadi bahan pembelajaran bagi pembaca untuk dapat memahami metode DEA.

\section{DAFTAR PUSTAKA}

Callen, J.L.(1991). Data Envelopment Analysis : Partial Survey and Applications for Management Accounting. Journal of Management Accounting Research, Vol 3, 35-56

Charnes, A. Cooper, W.W. Rhodes, E. (1978). Measuring the Efficiency of Decision Making Units. European Journal of Operation Research, Vol. 2, 429-444

Despotis, D.K \& Smirlis Y.G. (2002). Data Envelopment Analysis With Imprecise Data. European Journal of Operation Research, Vol. 140, 24-36 
Gonzales Bravo. (2007). Prior Ratio Analysis Procedure to Improve Data Envelopment Analysis for Performance Measurement. Journal of the Operational Research Society, Vol. 58, 1214-1222.

Gunawarman, H. \& Fanni, A.S. (2008). Implementasi Prinsip Kerja 5S Pada Bagian Pabrikasi 1 Untuk Meningkatkan Efisiensi Waktu Produksi. Jurnal Inasea, Vol. 9(2), 104-113

Innayatulloh. (2013). Pembangunan Model E-Learning di Perguruan Tinggi Untuk Meningkatkan Efisiensi Belajar Mengajar. Jurnal Comtech, Vol. 04(2), 612-617.

Ismaniah. Penyelesaian Masalah Riset Operasi (Transportasi) Dengan Menggunakan Program Solver. Jurnal Kajian Ilmiah Lembaga Penelitian Ubahar Jaya. Vol. 10(1)

Iswadorno S Permono. (2000). Analisis Efisiensi Industri Perbankan di Indonesia (Studi Kasus Bank-Bank Devisa di Indonesia Tahun 1991-1996). Jurnal Ekonomi dan Bisnis Indonesia, Vol. 15(1), 1-3

Joanna Nowakowska-Grunt. (2009). Strategy of Distribution in Food Industry Companies. Annales Universitatis Apulensis Series Oeconomica 11(2). Warsawa : Czestochowa University of Technology

Mumu D Huri, Susilowaty, I. (2004). Pengukuran Efisiensi Relatif Emiten Perbankan Dengan Metode Data Envelopment Analysis (DEA) (Studi Kasus:Bank-Bank Yang Terdaftar di Bursa Efek Jakarta Pada Tahun 2002). Jurnal Dinamika Pembangunan, Vol. 1(2), 95-110

Ramanatan, R.A. (2000). Holistic Approach to Compare Energy Effciencies of Different Transprt Modes. Journal of Energy Policy, Vol. 28(11), 743-747

Ruddy, T.S. (2010). Pengaruh Merger dan Akuisisi Terhadap Efisiensi Perbankan di Indonesia (Tahun1998-2009). Jurnal Akuntansi dan Keuangan, Vol. 12(2), 102-128 
Sahid Susilo Nugroho. Analisis DEA dan Pengukuran Efisiensi Merek. Jurnal Kelola-Gadjah Mada Business News, Vol. 8(4)

Soteriou Andreas, C. \& Stavrinides, Y. (2000). An Internal Customer Service Quality Data Envelopment Data Analysis Model for Bank Branches. International Journal of Bank Marketing, Vol. 18(5), 246-252.

Sugiyono. (2009). Metode Penelitian Kuantitatif Kualitatif dan R\&D. Edisi 8. Hal 137. Bandung : Alfabeta.

Talluri, S. (2000). Data Envelopment Analysis. Decision Line. Hal. 8-11. Pennsylvania State University 